\title{
Web Services for Incorporation of Air Quality and Climate Change in Long-Term Urban Planning for Europe
}

\author{
Magnuz Engardt ${ }^{1}$, Christer Johansson ${ }^{2,3}$, and Lars Gidhagen ${ }^{1}$ \\ ${ }^{1}$ Swedish Meteorological and Hydrological Institute, SE-601 76 Norrköping, Sweden \\ \{magnuz.engardt, lars.gidhagen\} @smhi.se \\ ${ }^{2}$ Stockholm Environment and Health Administration, Box 8136, \\ SE-104 20 Stockholm, Sweden \\ ${ }^{3}$ Department of Applied Environmental Science, Stockholm University, \\ SE-10691 Stockholm, Sweden \\ christer.johansson@itm.su.se
}

\begin{abstract}
Planning for sustainable cities requires the inclusion of environmental aspects like air quality. Within a planning perspective of 20-30 years, there are various factors influencing future air quality:

Worldwide: Climate change may change global background pollution levels and it will affect the atmospheric chemistry.

Europe: Many efforts are taken to reduce emissions of air pollutants and climate forcing agents. These efforts will contribute to changes in the levels of air pollution reaching European cities.

Locally: City populations will grow. The population growth, together with the design of transportation and energy production systems, influence the city's own contribution to air pollution.

The web-service presented allows end-users in an arbitrary European city to consider these factors impact on air quality. It also includes tools for visualization and standards for easy connection to existing local model systems in the cities.
\end{abstract}

Keywords: climate change, climate services, climate scenario, air quality modeling, urban planning.

\section{Introduction}

The FP7 ICT-2009-6.4 project SUDPLAN [1],[2] includes the development of a webbased ICT tool that will assist urban planners to incorporate future environment factors in the decision process. Due to its strong impact on citizens' health, comfort, safety and quality life it is important to also consider air quality in urban planning. For European cities, the future urban air quality will be determined by processes and decisions on very different scales. 
Climate change will alter the global background of pollutants and it will also affect the way the atmosphere reacts to air pollution emissions over Europe. Actions taken e.g. in form of emission ceilings for EU member states - may reduce emissions of both air pollutants and climate forcing agents. These efforts will, over decadal periods, contribute to changes in the levels of long range transported air pollution reaching European cities. On the local scale, city populations will grow and planners may opt for spatial expansion or for concentration. This, together with the design and technical developments of transportation and energy production systems, will determine how much local emissions will influence the future air quality.

Through the SUDPLAN web based user interface, named Scenario Management System (SMS), end-users in an arbitrary European city will be able to use a service for climate and environmental information: the Common Services (CS). CS offers as one component the visualization of how temperature and precipitation will evolve over Europe during the coming decades. The information consists of gridded 10-yearaverages for a certain period, currently the years of 1960-2100 output from SMHI's regional climate model RCA3 [3]. Available for SUDPLAN visualization is currently RCA3 downscaled results using the Global Climate Models (GCMs) ECHAM5 A1B [4],[5] and HADLEY A1B [6] as boundary conditions. An important aspect in SUDPLAN use of climate scenarios is an ensemble approach, i.e. to use various scenario results to illustrate the uncertainty in future climate.

SUDPLAN visualization on the European scale also includes scenarios of the evolution of $\mathrm{NOx}, \mathrm{NO}_{2}, \mathrm{O}_{3}$ and PM10. These air quality results stem from simulations with the regional dispersion model MATCH [7], forced by meteorological data from RCA3 simulating different climate change realizations. In order to include a realistic temporal evolution of European primary and precursor emissions, the MATCH model has used the RCP4.5 emission scenario [8] to assess air quality impact of the ECHAM5 A1B and HADLEY A1B climate scenarios. SUDPLAN will, in the near future, replace the current GCM and RCA3 results from the IPPC fourth assessment's A1B scenario with the new results based on RCP emissions also on the global scale.

SUDPLAN offer European cities downscaling of future rainfall, hydrological conditions and air quality. The focus of this paper is the urban air quality downscaling that can be performed with the European scale climate and air pollution as input. In what follows the downscaling procedure is described, how this is performed by the end-user and how the results can be presented. We will also evaluate the downscaling model results against measured air quality. All results are taken from Stockholm, one of four SUDPLAN pilot cities.

\section{Methods}

The following sections describe the chemistry transport model MATCH used for the downscaling and how it is used in the SUDPLAN tool. 


\subsection{Air Quality Downscaling Model}

To determine future air quality over a city we use a dedicated version of the threedimensional off-line CTM MATCH [7], operated over the city of concern. The domain is flexible and set by the user - typically $100 \times 100 \mathrm{~km}^{2}$ with $50-100$ grids in each horizontal direction. This model is driven by high-resolution tracer emissions from a local emission inventory and interpolated meteorology from a regional climate model. Local emission scenarios should represent both present (reference) and future conditions, the latter based on assumptions about traffic solutions and future population densities, etc. In the SMS it will be possible to operate the urban-scale model with different local emission scenarios, thus executing the model a number of times. As outlined in the introduction, the meteorology from the regional climate model is also driving a version of MATCH operating on courser resolution to calculate concentrations of tracers in Europe, following climate change and variations of tracer emissions.

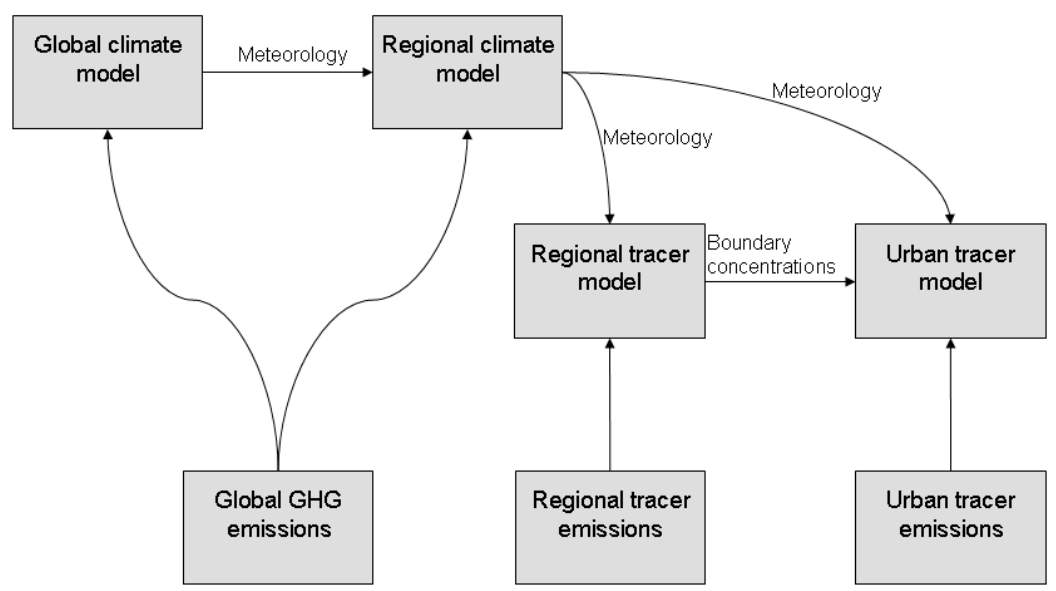

Fig. 1. SUDPLAN models. Linking global climate change to future air quality. A sequential approach.

The SUDPLAN SMS user interface lists an ensemble of climate simulations and European-scale air quality simulations representing different climate change realizations and different European tracer emission scenarios. These results are available as boundary conditions to the urban air quality downscaling.

\subsection{Air Quality Downscaling in Common Services}

The basic principle for SUDPLAN Common Services (CS) is that the end-user provides local data to improve the downscaling of environmental information reflecting a future climate change. This means that the end-user operating the SUDPLAN user interface, the Scenario Management System (SMS), will transfer data both to and from CS, and they will also operate models inside CS. For air quality downscaling the 
transfer of time series or gridded data is through Sensor Observation Services (SOS) and the model execution takes place through the Sensor Planning Services (SPS), see Table 1. The use of these two standard interfaces will allow also external users to access CS information, without using the SMS user interface.

Table 1. Overview of standardized interfaces (OGC) used to access Common Services

\begin{tabular}{lcccc}
\hline \multicolumn{1}{c}{ Model } & SOS & SPS & WMS & WFS \\
\hline European scale visualisation & X & & X & \\
Rainfall downscaling & X & X & & \\
Hydrological downscaling & X & X & & X \\
Air quality downscaling & X & X & & \\
\hline
\end{tabular}

Fig. 2 illustrates the data flows and user options while doing an air quality downscaling. Local emissions may be uploaded to CS as spatial grids of annual averaged emissions for NOx, SOx, CO, VOC, NH3 and PM10. Temporal variations for each grid are described as tables for monthly and daily variations. Uploaded emissions are stored in a CS emission database, so that upload of a specific emission scenario is only made once.

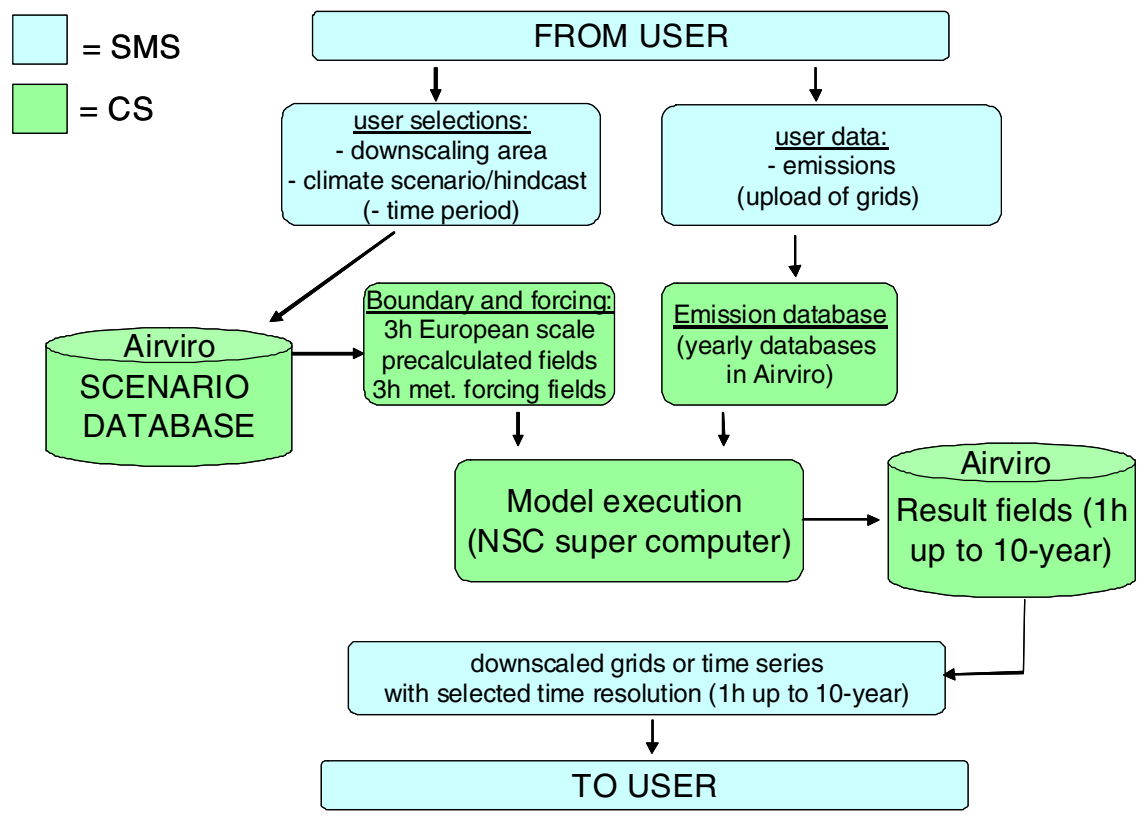

Fig. 2. Work flows in Common Services

Other options for the end-user is defining grid size and simulation area, emission database, simulation period and which European scale result to use as forcing and boundary conditions (see preceding section of details). During model execution there 
will be status messages sent to the SMS user interface, notifying when the simulation is completed. Downscaled results are available as 10-year, yearly, monthly and daily averaged grids. For shorter simulation periods up to one year, also hourly grids will be available (allowing extreme values to be visualized statistically compared to relevant limit values).

\section{Air Quality Downscaling Results}

To demonstrate the performance of the urban downscaling Fig. 3 shows observed concentrations of NOX, $\mathrm{NO}_{2}, \mathrm{O}_{3}$ and PM10 at Torkel Knutssonsgatan and Norr Malma during 2009 and 2010 together with calculated concentrations of these species. The calculations were all done on the same domain covering Stockholm and its surroundings, utilizing identical emission inventory but meteorology and tracer boundaries concentrations from different sources.
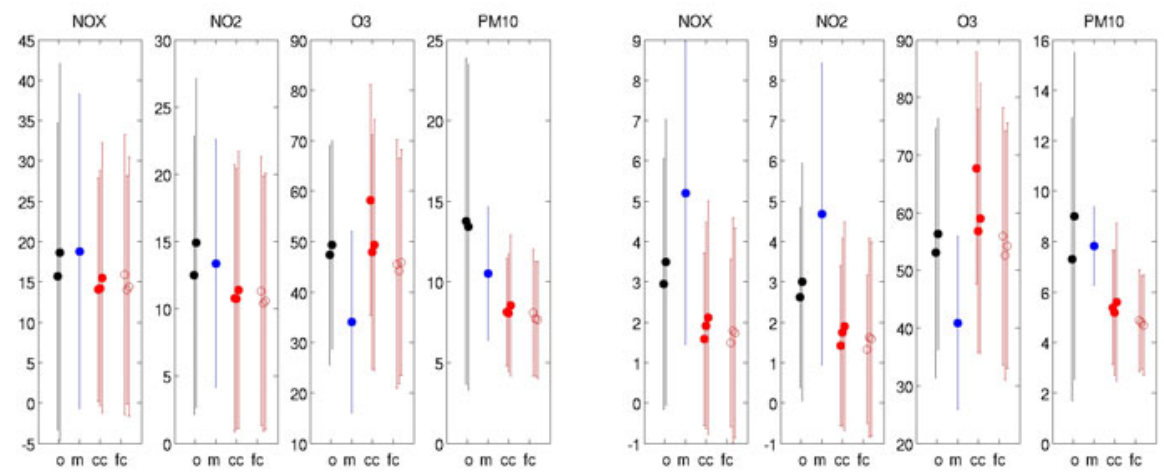

Fig. 3. Annual average concentration of $\mathrm{NOX}, \mathrm{NO}_{2}, \mathrm{O}_{3}$ and $\mathrm{PM} 10$ at the urban background site Torkel Knutssonsgatan (left), and a rural site Norr Malma (right). Black dots are measurements collected during 2009 and 2010. Blue dot is model simulations for the year 2010. Red dots are model simulations using climate data representative of two years close to 2010. Red rings are model simulations using climate data representative of two years close to 2030. Bars represent \pm one standard deviation of hourly mean values. All concentrations are given in $\mu \mathrm{g} \mathrm{m}^{-3}$.

Fig. 3 shows that the observed variability between two consecutive years is as large as the year-to-year variability of the simulations driven by the European climate data. The results show that $\mathrm{MATCH}$ reproduces $\mathrm{NOx}, \mathrm{NO}_{2}$ and $\mathrm{O}_{3}$ well, at both sites but underestimate PM10 at both sites. The simulations utilizing meteorology from a climate model performs equally reasonable as the simulations using "real" meteorology. The underestimation of PM10 is expected due to omissions of certain sources in the present set-up. Omitted sources include non-tailpipe emissions, which contribute significantly to PM10 in the Stockholm region [9], [10], [11].

Fig. 4 and 5 show 3-year averaged concentrations of $\mathrm{NO}_{2}$ and $\mathrm{O}_{3}$ centered in 2010 and 2030. In this example, the change between the two periods is only brought about by changes in European tracer emissions and changes in climate. Note that the data is 
the result of a chain of three-dimensional meteorological and air quality models, operating with hourly resolution over multi-year periods. The figures demonstrate that the background concentration of $\mathrm{NO}_{2}$ and $\mathrm{O}_{3}$ will decrease in the future - mainly as a result of reduced precursor emissions in Europe. Other studies have shown that climate change may, to some extent and in particular in continental Europe, counteract the positive effects on ozone levels achieved by reduced precursor emissions [12]. In Stockholm it seems that the effect of reduced precursor emissions in Europe will have a dominating positive effect on average ozone levels.
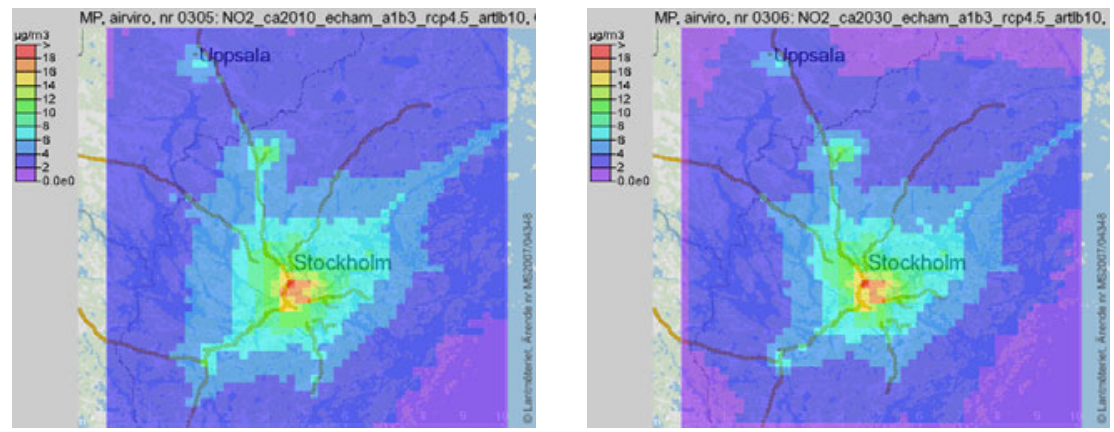

Fig. 4. 3-year average $\mathrm{NO}_{2}$ concentration (ca. 2010 left, ca. 2030 right). The simulations depict a situation where the local emissions were kept at the levels of 2010, but meteorology and climate were changing according to the ECHAM A1B scenario and European tracer emissions following RCP4.5.
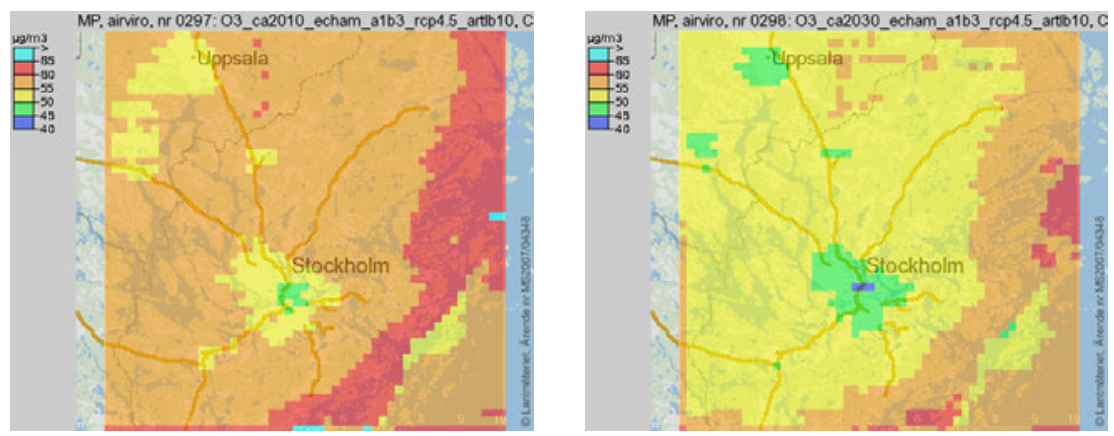

Fig. 5. 3-year average $\mathrm{O}_{3}$ concentration (ca. 2010 left, ca. 2030 right). The simulations depict a situation where the local emissions were kept at the levels of 2010, but meteorology and climate were changing according to the ECHAM A1B scenario and European tracer emissions following RCP4.5.

\section{Conclusions}

The SUDPLAN air quality downscaling model system has been executed over the Stockholm region and reproduces observed concentration of $\mathrm{NOx}, \mathrm{NO}_{2}$, and $\mathrm{O}_{3}$ well. The average concentration and variability of PM10 is underestimated, however this is 
expected since all sources of PM10 are not included in the simulations. From comparisons between simulations with "observed" meteorology and simulations with meteorology from a climate model represented "current climate" it is deduced that the climate data is well suited for describing current climate. Using one particular climate realization (ECHAM5 A1B) together with one tracer emission scenario (RCP4.5) result in decreasing concentrations of air pollutants NO2 and O3 in Stockholm from 2010 to 2030 - mostly a result of decreasing precursor emissions. Other studies have shown that climate change may counteract the positive impact resulting from emission reductions over Europe.

The SUDPLAN scenario management system (SMS), together with the Common Services (CS), are developed to investigate the effect of different climate scenarios and different tracer emissions over Europe. The Sudplan tool also permits the utilization of different emissions scenarios in specific cities. In the present study we investigated the result of changing tracer emissions in Europe together with changing climate, but maintaining local city emissions at a fix (today's) level. The next step will be to include also the effect of different political decisions taken in a particular city, decisions that will alter local emissions. For example, what will be the effect of a certain city bypass, or a general increase of the vehicle fleet.

Acknowledgments. SUDPLAN is a Collaborative Project (contract number 247708) co-funded by the Information Society and Media DG of the European Commission within the RTD activities of the Thematic Priority Information Society Technologies.

\section{References}

1. Gidhagen, L., Denzer, R., Schlobinski, S., Michel, F., Kutschera, P., Havlik, D.: Sustainable Urban Development Planner for Climate Change Adaptation (SUDPLAN). In: Berre, A., Roman, D., Maué, P. (eds.) Proceedings of ENVIP 2010 Workshop at EnviroInfo2010, "Environmental Information Systems and Services - Infrastructures and Platforms, Bonn, October 6-8. CEUR-WS, vol. 679 (2010) ISSN 1613-0073, urn:nbn:de:0074-679-9

2. Denzer, R., Schlobinski, S., Gidhagen, L.: A Decision Support System for Urban Climate Change Adapatation. In: Proceedings of the 44th Hawaii International Conference on System Sciences (2011)

3. Kjellström, E., Nikulin, G., Hansson, U., Strandberg, G., Ullerstig, A.: 21st century changes in the European climate: uncertainties derived from an ensemble of regional climate model simulations. Tellus, 63A (2011)

4. Roeckner, E., Brokopf, R., Esch, M., Giorgetta, M., Hagemann, S., et al.: Sensitivity of simulated climated to horizontal and vertical resolution in the ECHAM5 atmosphere model. J. Clim. 19 (2006)

5. Jungclaus, J.H., Botzet, M., Haak, H., Keenlyside, N., Luo, J.-J., et al.: Ocean cireculation and tropical variability in the coupled ECHAM5/MPI-OM. J. Clim., 19 (2006)

6. Gordon, C., Cooper, C., Senior, C.A., Banks, H., Gregory, J.M., et al.: The simulation of SST, sea ice extents and ocean heat transports in a version of the Hadley Centre coupled model without flux adjustments. Clim. Dyn., 16 (2000)

7. Robertson, L., Langner, J., Engardt, M.: An Eulerian limited-area atmospheric transport model. J. Appl. Meteorol. 38 (1999) 
8. Moss, R.H., Edmonds, J.A., Hibbard, K.A., Manning, M.R., Rose, S.K., van Vuuren, D.P., Carter, T.R., Emori, S., Kainuma, M., Kram, T., Meehl, G.a., Mitchell, J.F.B., Nakicenovic, N., Riahi, K., Smith, S.J., Stouffer, R.J., Thomson, A.M., Weaynt, J.P., Wilbanks, T.J.: The next generation of scenarios for climate change research and assessment. Nature 463 (2010)

9. Norman, M., Johansson, C.: Studies of some measures to reduce road dust emissions from paved roads in Scandinavia. Atmos. Environ. 40, 6154-6164 (2006)

10. Johansson, C., Norman, M., Gidhagen, L.: Spatial \& temporal variations of PM10 and particle number concentrations in urban air. Environ. Monit. Assess. 127, 477-487 (2007), doi:10.1007/s10661-006-9296-4

11. Omstedt, G., Johansson, C., Bringfelt, B.: A Model for vehicle Induced Non-tailpipe Emissions of Particles Along Swedish Roads. Atmos. Environ. 39, 6088-6097 (2005)

12. Engardt, M., Bergström, R., Andersson, C.: Climate and Emission Changes Contributing to Changes in Near-surface Ozone in Europe over the Coming Decades: Results from Model Studies. Ambio. 38(8), 452-458 (2009) 